\title{
Combined Toxicity of Nitro-Substituted Benzenes and Zinc to Photobacterium Phosphoreum: Evaluation and QSAR Analysis
}

\author{
Shengnan Zhang ${ }^{1}$, Limin Su ${ }^{1, *}$, Xujia Zhang ${ }^{1,2}$, Chao Li $^{1}$, Weichao Qin ${ }^{1}$, Dongmei Zhang ${ }^{1}$, \\ Xiaoxia Liang ${ }^{1}$ and Yuanhui Zhao ${ }^{1, *}$ \\ 1 School of Environment, and State Environmental Protection Key Laboratory of Wetland Ecology \\ and Vegetation Restoration, Northeast Normal University, Changchun 130117, China; \\ zhangsn432@nenu.edu.cn (S.Z.); zhangxj957@nenu.edu.cn (X.Z.); lic932@nenu.edu.cn (C.L.); \\ qinwc425@nenu.edu.cn (W.Q.); zhangdm941@nenu.edu.cn (D.Z.); liangxx512@nenu.edu.cn (X.L.) \\ 2 College of Geographical Sciences, Harbin Normal University, Harbin 150025, China \\ * Correspondence: sulm932@nenu.edu.cn (L.S.); zhaoyh@nenu.edu.cn (Y.Z.)
}

Received: 17 February 2019; Accepted: 21 March 2019; Published: 22 March 2019

\begin{abstract}
The single toxicity $\left(\mathrm{IC}_{50}\right)$ of zinc $(\mathrm{Zn})$ and 11 nitro-substituted benzenes to Photobacterium phosphoreum were determined, respectively. On basis of single toxicity, the joint toxicity of binary mixtures of $\mathrm{Zn}$ and 11 nitro-substituted benzenes at different $\mathrm{Zn}$ concentrations of $0.2 \mathrm{IC}_{50}, 0.5 \mathrm{IC}_{50}$, and $0.8 \mathrm{IC}_{50}$ were measured. The joint toxicity was evaluated by toxic unit (TU) and additive index (AI) methods. The results indicated that the joint toxicity was not only depending on the $\mathrm{Zn}$ concentrations but also on the substituted groups of nitro-substituted benzenes. The quantitative structure-activity relation (QSAR) equations were developed and the results showed that the toxicity of nitro-substituted benzenes has different joint effect at the different $\mathrm{Zn}$ concentrations. At the Zn concentration of $0.2 \mathrm{IC}_{50}$, the binary joint effects were mainly antagonism and the joint toxicity was negatively related to descriptors called VE2_B(p) and TIC3. At the Zn concentration of $0.5 \mathrm{IC}_{50}$ and $0.8 \mathrm{IC}_{50}$, the binary joint effects were mainly antagonism and simple addition, and the joint toxicity was related to the same descriptor Eig06_ AEA $(\mathrm{dm})$. It indicated that the joint toxic actions were similar when combined at the medium and high concentrations of $\mathrm{Zn}$.
\end{abstract}

Keywords: joint toxicity; QSAR; substituted benzenes; Photobacterium phosphoreum; zinc

\section{Introduction}

It is obviously that the risks of chemical pollutants are mostly evaluated on the single toxicity value of a chemical and the adverse effects or single actions of chemicals have received extensive attention [1-4]. Although it is crucial to identify and characterize harmful effects from pollutants on different organisms, it is incontestable that those results are not enough to tell what happens in the real environment [5]. After all, contaminants are introduced into the aquatic ecosystems as complex blends. When the chemicals collectively exist, it is worth taking into account that certain pollutant combinations may interact and result in different interactions toxic effects on ecosystems or organisms [5,6]. Interactions of components in a mixture can cause complex and substantial changes in the apparent properties of its constituents [7]. The joint effect of toxicants could be less than, equal to, or greater than the sum of the effects of the individual toxicants which is often expected, and correspondingly the toxicity of toxicants could be described as antagonistic, additive, or synergistic [8,9]. The use of single toxicity data may fail to predict associated effects and interactions of chemicals in mixture and so is limited to cast light on ecological risk in naturally contaminated 
aquatic environments [10-13]. Therefore, realistic safe limits on basis of co-occurrence of chemicals needs to be considered for environmental management.

Nitro-substituted benzenes, used in a broad range of fields as important raw materials and products of chemical industry, have been widely determined in the municipal wastewater and aquatic environments. They have been thought to be an important class of environmental contaminants [14]. Many nitro-substituted benzenes and their transformation products are toxic and some cases even carcinogenic $[15,16]$. Heavy metals are ubiquitous and persistent pollutants in the environment. They can be easily accumulated in organism by bio-concentration and bio-magnification and finally endanger the health of human beings [17]. Zn, as one of the heavy metals, is extensively used by numerous industries mainly in galvanization and in the manufacture of brass and other alloys, and it is introduced to surface waters due to activities of humans as both point and nonpoint source [18]. $\mathrm{Zn}$ is nutritionally essential elements and thus its toxic effects are relatively less in comparison to other more potent nonessential metals. However, it can induce toxic effects on the hematopoietic system, biochemistry, and endocrine system function when exposures exceeded required concentrations [19]. A study found that $\mathrm{Zn}$ (II) is toxic for humans at levels of $100-500 \mathrm{mg} / \mathrm{d}$ [18].

Most studies have been carried out on the combined toxicity between $\mathrm{Zn}$ and other heavy metals [20-22]. There are also few studies that focus on the joint toxicity of $\mathrm{Zn}$ and organic chemicals [23,24]. Liu et al. [23] investigated the joint toxicity of perfluorooctane sulfonate (PFOS) and zinc and the results show that the combined effects of the PFOS and Zn binary mixture to Limnodrilus hoffmeisteri were mostly simple addition. $\mathrm{Zn}$ and PFOS were also found to evoke some changes in the antioxidant defense system, and a strong self-adaptive ability was noticed after 10d exposure. With the combined treatment of $\mathrm{Zn}$ and Cefradine, the bacterial Pseudomonas fluorescens YZ2 resistance was improved showing a more significant increase of total superoxide dismutase (SOD) activity and therefore it is found that the binary stress induced the bacterial resistance by regulating SOD activity to eliminate reactive oxidative species (ROS) [24].

Until now, the joint interaction of nitro-substituted benzenes and $\mathrm{Zn}$ to organisms in aquatic ecosystem is poorly understood and little knowledge regarding their potential to produce additive toxicity or non-additive toxicity (i.e., antagonism or potentiation) although, as the common contaminants, the mixtures of heavy metal $\mathrm{Zn}$ and nitro-substituted benzenes occur inevitably and ubiquitously in aquatic environments. They have been detected simultaneously in Chinese surface water, such as Songhua River, Yellow River, and Yangtze River [25-27]. In this sense, the study was carried out to investigate the joint toxicity of nitro-substituted benzenes and $\mathrm{Zn}$ and thus to provide information for environmental pollution diagnosis and ecological risk assessment in aquatic environments.

In the present paper, the aquatic organism, Photobacterium phosphoreum, was chosen as the test organism for the method is easy to perform, robust and widely used as screening method for testing toxicity of organic chemicals $[28,29]$. Single toxicity of nitro-substituted benzenes and $\mathrm{Zn}$ were determined, respectively. In order to investigate combined ratios to the joint toxic effect, mixture toxicity was determined by setting three different levels of $\mathrm{Zn}$ concentrations (low, medium, and high concentrations). The objectives of paper are: firstly, to evaluate the acute toxic effect of mixtures between nitro-substituted benzenes and metal Zn; secondly, to establish models and investigate the relationships between joint toxicity and calculated molecular descriptors at different Zn concentrations using the quantitative structure-activity relationships (QSARs) method, and try to analyze property or structure factors that govern the combined toxicity of nitro-substituted benzenes to P. phosphoreum; thirdly, to provide robust models to predict the toxicity of more nitro-substituted benzenes when they coexist with $\mathrm{Zn}$. 


\section{Materials and Method}

\subsection{Chemicals}

Nitro-substituted benzenes were purchased from Jilin Haotian Chemical Reagent Co. (Jilin, China) and the purity was $98 \%$ or higher. The compounds used for preparation of liquid medium were of chemically pure quality. The toxicity of $\mathrm{Zn}$ was evaluated using zinc (II) chloride $\left(\mathrm{ZnCl}_{2}\right.$, purity of $>99 \%$ ) which was purchased from Beijing Chemical Reagent Factory. Each stock solution of $\mathrm{Zn}$ or tested nitro-substituted benzenes was prepared in deionized water containing $3 \% \mathrm{NaCl}$ so as maintain the salinity for P. phosphoreum, which live in a marine environment. The ultrasonic instrument (KQ3200I, made by Kunshan Ultrasonic Instrument Co., Kunshan, China) was utilized to accelerate dissolution for those organic compounds.

\subsection{Bioassay}

Test organism, $P$. phosphoreum, appropriating for the experimental of joint effects, was served in the form of freeze-dry powder supplied by the Nanjing Institute of Soil Science, Chinese Academy of Science. The culture medium of P. phosphoreum was prepared according to Su et al. [20-31] and Yuan et al. [32]. The constituents of culture medium are shown in Table 1.

Table 1. Constituents of culture medium for P. phosphoreum.

\begin{tabular}{cccccc}
\hline No. & Compounds & Contents & No. & Compounds & Contents \\
\hline 1 & Barm lixiviating & $0.5 \mathrm{~g}$ & 4 & $\mathrm{Na}_{2} \mathrm{HPO}_{4}$ & $0.5 \mathrm{~g}$ \\
2 & extract & $0.5 \mathrm{~g}$ & 5 & $\mathrm{KH}_{2} \mathrm{PO}_{4}$ & $0.1 \mathrm{~g}$ \\
3 & Peptone & $0.3 \mathrm{~g}$ & 6 & $\mathrm{NaCl}$ & $3.0 \mathrm{~g}$ \\
\hline
\end{tabular}

All the constituents were put into the volumetric flask and diluted using $100 \mathrm{~mL}$ deionized water. The $\mathrm{pH}$ of the culture medium was adjusted to $7.0 \pm 0.5$, then the medium was sterilized for $20 \mathrm{~min}$ at $121^{\circ} \mathrm{C}$. The freeze-dry powder of $P$. phosphoreum was dissolved using $0.5 \mathrm{~mL}$ of $3 \% \mathrm{NaCl}$ solution, and then inoculated into $50 \mathrm{~mL}$ of culture medium at $21^{\circ} \mathrm{C}$.

Single toxicity of each nitro-substituted benzenes to $P$. phosphoreum or $\mathrm{Zn}$ was measured in the laboratory. After the preliminary experiments, each compound was set five treatment concentrations from low to high by equal interval of logarithm. Three replicates were set for each treatment concentration including the control group (solution only containing $3 \% \mathrm{NaCl}$ in deionized water) [28-33]. For each treatment concentration, a medium solution containing diluted P. phosphoreum of $0.5 \mathrm{~mL}$ was inoculated into a tube containing $2 \mathrm{~mL}$ of a tested chemical solution or a $3 \% \mathrm{NaCl}$ solution as control. After exposure of $15 \mathrm{~min}$, the bioluminescence of the tested tube was detected by Microtox toxicity analyzer (DXY-2, made by the Nanjing Institute of Soil Science, Chinese Academy of Science, Nanjing, China). The inhibition rate of bioluminescence was calculated as

$$
\text { inhibition rate }(\%)=\frac{\text { the reduction of bioluminescence of each compound solution }}{\text { the bioluminescence of the control one }} \times 100 \%
$$

The median inhabiting concentration was expressed as $\mathrm{IC}_{50}$ and implies that the tested compound concentration causes a $50 \%$ inhibition on the bioluminescence of $P$. phosphoreum. The $\mathrm{IC}_{50}$ value (expressed in mol/L) of each tested compound and its corresponding confidence interval (CI) at 95\% was calculated by method of Probit analysis [34] with the SPSS statistic package (version 19.0, SPSS Company, Chicago, IL, USA).

To investigate the influence of combined ratios to the binary joint effects of $\mathrm{Zn}$ and each nitroaromatic compound towards P. phosphoreum, Zn concentration was set at three concentrations, $0.2,0.5$, and $0.8 \times \mathrm{IC}_{50}$ of $\mathrm{Zn}$ (low, medium, and high levels). The mixture toxicity test was conducted by using a single concentration of $\mathrm{Zn}$ combined with five concentrations of the tested 
nitroaromatic compound which varied from low to high by equal interval of logarithm. The $\mathrm{IC}_{50}$ of each nitroaromatic compound at each concentration of $\mathrm{Zn}$ was obtained from the five concentrations of the nitroaromatic compound and percentage of inhibiting bioluminescence by method of Probit analysis. Other procedures for the joint toxicity test are the same with the individual toxicity.

\subsection{Calculation of Descriptors}

The physico-chemical descriptors of nitro-substituted benzenes were calculated using DRAGON software (version 6.0, TALETE srl, Milano, Italy) on basis of molecular optimization [35,36]. Descriptors with constant or high pair-wise correlation were removed. A total of 361 descriptors were used for further analysis to develop QSAR models.

\subsection{Statistical Analysis of QSAR Models}

QSAR models were developed by using the stepwise linear regression method in the statistic package SPSS19.0 (SPSS Company, Chicago, IL, USA). Model quality was characterized by the number of observations (n), the square of the correlation coefficient $\left(R^{2}\right)$, the standard error of estimate (SE), Fisher's criterion $(\mathrm{F})$, and a significance level $(\mathrm{P})$.

\subsection{Evaluation Methods of Joint Toxicity}

Toxic unit (TU) and additive index (AI) [37-39] were used in this paper to analyze and quantify the joint effects of mixtures. A TU is defined as the concentration of a particularly toxic chemical in a mixture divided by the incipient or the threshold concentration which is the exposed concentration of a chemical that causes a certain biological response end point in question $(\mathrm{x} \%)$. This concept is mathematically expressed for the components of a mixture as formula

$$
\mathrm{TU}_{\mathrm{i}}=\frac{c_{\mathrm{i}}}{\mathrm{EC} x_{\mathrm{i}}}
$$

where, $\mathrm{TU}_{\mathrm{i}}$ is the toxic unit of chemical in an n-component mixture, $\mathrm{c}_{\mathrm{i}}$ is the concentration of a chemical $\mathrm{i}$ that causes a certain response $(\mathrm{x} \%)$ in that mixture, and $\mathrm{ECx}_{\mathrm{i}}$ is the concentration of the chemical causing the same response when acting alone. If the sum of $\mathrm{TU}_{\mathrm{i}}$ is $\mathrm{M}\left(\mathrm{M}=\Sigma \mathrm{TU}_{\mathrm{i}}\right)$, the additive index (AI) can be calculated according to the formulas (3) and (4)

$$
\begin{gathered}
\mathrm{AI}=1 / \mathrm{M}-1.0(\mathrm{M} \leq 1) \\
\mathrm{AI}=1.0-\mathrm{M}(\mathrm{M}>1)
\end{gathered}
$$

The joint effects are characterized as the following: when $\mathrm{M}=1$ or $\mathrm{AI}=0$, the joint effect is considered to be simple addition; when $\mathrm{M}<1$ or $\mathrm{AI}>0$, synergism; when $\mathrm{M}>1$ or $\mathrm{AI}<0$, antagonism.

\section{Results and Discussion}

\subsection{Single Toxicity of Nitro-Substituted Benzenes and Zn}

The single toxicity of 11 nitro-substituted benzenes and $\mathrm{Zn}$ to P. phosphoreum were determined and showed in Table 2. 
Table 2. Single toxicity and corresponding confidence interval at $95 \%$ of nitro-substituted benzenes and $\mathrm{Zn}$ to P. phosphoreum.

\begin{tabular}{|c|c|c|c|}
\hline No. & Compounds & CAS * & $\begin{array}{l}\text { Experimental Single Toxicity and } \\
\text { Corresponding Confidence Interval at } 95 \% \\
\left(\log 1 / \mathrm{IC}_{50}\right) /\left(\mathrm{mol} \mathrm{L}^{-1}\right)\end{array}$ \\
\hline 1 & nitrobenzene & $98-95-3$ & $3.20(3.14-3.25)$ \\
\hline 2 & $o$-dinitrobenzene & $528-29-0$ & $4.33(4.25-4.41)$ \\
\hline 3 & $m$-nitrobromobenzene & $585-79-5$ & $4.09(4.02-4.16)$ \\
\hline 4 & $p$-nitrobromobenzene & $586-78-7$ & $4.45(4.40-4.48)$ \\
\hline 5 & $o$-nitroaniline & $88-74-7$ & $3.71(3.64-3.78)$ \\
\hline 6 & $p$-nitroaniline & $100-01-6$ & $4.01(3.98-4.04)$ \\
\hline 7 & $p$-nitrobenzoic acid & $62-23-7$ & 3.81 (3.69-3.89) \\
\hline 8 & o-nitrophenol & $88-75-5$ & $3.44(3.37-3.52)$ \\
\hline 9 & $m$-nitrophenol & $554-84-7$ & $3.33(3.30-3.36)$ \\
\hline 10 & p-nitrophenol & $100-02-7$ & $4.11(3.99-4.23)$ \\
\hline 11 & 2,4-dinitrophenol & $51-28-5$ & $4.22(4.17-4.28)$ \\
\hline 12 & $\mathrm{Zn}\left(\mathrm{ZnCl}_{2}\right)$ & $7646-85-7$ & $5.13(5.06-5.21)$ \\
\hline
\end{tabular}

The result shows that the single toxicity of nitro-substituted benzenes is related to the position of substituted group. For the same substituted groups, the toxicities of para-substituted nitro-benzenes are more than those of ortho-substituted nitro-benzenes, and then metra-substituted nitro-benzenes. Heavy metal $\mathrm{Zn}$ is more toxic than 11 nitro-substituted benzenes.

\subsection{Evaluation of Joint Toxicity of Nitro-Substituted Benzenes and Zn}

The joint toxicity of nitro-substituted benzenes when they were combined with $\mathrm{Zn}$ at low, medium and high concentrations was listed in Table 3. There are only two joint actions, synergism and antagonism, between nitro-substituted benzenes and $\mathrm{Zn}$ if we strictly obey the criteria of AI or TU (33\% of the joint actions are synergism and $67 \%$ antagonism). It is widely acknowledged that within experimental error, it is an ideal situation and extremely difficult to obtain simple addition with $\mathrm{M}=1$ or $\mathrm{AI}=0[28,30,31,40,41]$. Broderius et al. [41] defined simple addition with $\mathrm{M}$ values equal to $1 \pm 0.2$. A simple addition is characterized by $1.2>\mathrm{TU}$ (or $\mathrm{M}$ ) $>0.8$, whereas $\mathrm{TU}$ (or $\mathrm{M}$ ) $\geq 1.2$ represents antagonism and $\mathrm{TU}$ ( or $\mathrm{M}) \leq 0.8$ indicates synergism in the studies of combined toxicity of antibiotics and quorum sensing inhibitors against Escherichia coli [28,40]. In this paper, it is referred to the methods by the above studies to define the evaluation criteria, that is, simple addition is defined as $1.2>\mathrm{M}>0.8$ or $-0.2<\mathrm{AI}<0.25$. The evaluated results of the joint toxicity were shown in Figure 1.

As shown in Figure 1, at the $\mathrm{Zn}$ concentration of $0.2 \mathrm{IC}_{50}$, the binary mixtures of $\mathrm{Zn}$ and 7 nitro-substituted benzenes (nitrobenzene, $m$-nitrobromobenzene, $p$-nitrobromobenzene, $o$-nitroaniline, $p$-nitroaniline, o-nitrophenol, $p$-nitrophenol) showed antagonism with $\mathrm{M}$ ranging from 1.22 to 1.65 and AI ranging from -0.65 to -0.22 . The mixtures of $\mathrm{Zn}$ and 5 nitro-substituted benzenes (nitrobenzene, $m$-nitrobromobenzene, $p$-nitrobromobenzene, $o$-nitroaniline, $p$-nitroaniline) all showed antagonism at any $\mathrm{Zn}$ concentration $\left(0.2 \mathrm{IC}_{50}, 0.5 \mathrm{IC}_{50}\right.$, or $\left.0.8 \mathrm{IC}_{50}\right)$. Other binary mixtures are mainly simple addition. The joint toxicity of $p$-nitrobenzoic acid and $\mathrm{Zn}$ (at the concentration of $0.2 \mathrm{IC}_{50}$ and $0.5 \mathrm{IC}_{50}$ ) was exceptions which showed synergism. In general, the joint effects showed mainly antagonism and simple addition when $\mathrm{Zn}$ combined with nitro-substituted benzenes. The result is consistent with the research by Cedergreen [42] who found that synergistic interactions between chemicals are rare. 
Table 3. Toxicity of nitro-substitutions and Zn.

\begin{tabular}{|c|c|c|}
\hline Mixture & $\mathrm{Zn}\left(\mathrm{IC}_{50}\right)$ & $\begin{array}{l}\text { Toxicity of Nitro-Substituted Benzenes in } \\
\text { Mixtures and CI at } 95 \% \\
\left(\log 1 / \mathrm{IC}_{50}\right) /\left(\mathrm{mol} \mathrm{L}^{-1}\right)\end{array}$ \\
\hline \multirow{4}{*}{$\mathrm{Zn}+$ nitrobenzene } & 0.2 & $3.04(2.98-3.08)$ \\
\hline & 0.5 & $3.18(3.13-3.24)$ \\
\hline & 0.8 & $3.15(3.08-3.23)$ \\
\hline & 0.2 & $4.41(4.34-4.48)$ \\
\hline \multirow{3}{*}{$\mathrm{Zn}+o$-dinitrobenzene } & 0.5 & $4.67(4.58-4.76)$ \\
\hline & 0.8 & $5.17(5.07-5.31)$ \\
\hline & 0.2 & $4.08(4.01-4.14)$ \\
\hline \multirow[t]{3}{*}{$\mathrm{Zn}+m$-nitrobromobenzene } & 0.5 & $4.05(3.96-4.13)$ \\
\hline & 0.8 & $4.20(4.11-4.30)$ \\
\hline & 0.2 & $4.42(4.38-4.45)$ \\
\hline \multirow[t]{3}{*}{$\mathrm{Zn}+p$ - nitrobromobenzene } & 0.5 & $4.30(4.25-5.36)$ \\
\hline & 0.8 & $4.62(4.43-4.83)$ \\
\hline & 0.2 & $3.68(3.61-3.74)$ \\
\hline \multirow[t]{3}{*}{$\mathrm{Zn}+o$-nitroaniline } & 0.5 & $3.67(3.62-3.71)$ \\
\hline & 0.8 & $3.76(3.69-3.86)$ \\
\hline & 0.2 & $3.97(3.89-4.04)$ \\
\hline \multirow{3}{*}{$\mathrm{Zn}+p$-nitroaniline } & 0.5 & $3.91(3.87-3.93)$ \\
\hline & 0.8 & $3.89(3.87-3.92)$ \\
\hline & 0.2 & $4.91(4.80-4.99)$ \\
\hline \multirow[t]{3}{*}{$\mathrm{Zn}+p$-nitrobenzoic acid } & 0.5 & $5.14(5.06-5.27)$ \\
\hline & 0.8 & $5.58(5.46-5.73)$ \\
\hline & 0.2 & $3.33(3.21-3.45)$ \\
\hline \multirow[t]{3}{*}{$\mathrm{Zn}+o$-nitrophenol } & 0.5 & $3.82(3.64-3.96)$ \\
\hline & 0.8 & $4.21(4.02-4.42)$ \\
\hline & 0.2 & $3.35(3.26-3.47)$ \\
\hline \multirow[t]{3}{*}{$\mathrm{Zn}+m$-nitrophenol } & 0.5 & $3.51(3.41-3.62)$ \\
\hline & 0.8 & $3.79(3.68-3.95)$ \\
\hline & 0.2 & $3.98(4.05-4.20)$ \\
\hline \multirow{3}{*}{$\mathrm{Zn}+p$-nitrophenol } & 0.5 & $4.45(4.33-4.51)$ \\
\hline & 0.8 & $4.68(4.42-4.87)$ \\
\hline & 0.2 & $4.32(4.19-4.47)$ \\
\hline \multirow[t]{2}{*}{$\mathrm{Zn}+2$,4-dinitrophenol } & 0.5 & $4.63(4.52-4.79)$ \\
\hline & 0.8 & $5.38(5.16-5.54)$ \\
\hline
\end{tabular}

Among joint actions, synergistic interaction of chemicals in mixtures is an area of great concern to both the public [43] and regulatory authorities because some chemicals can enhance the effect of other chemicals, and they jointly exert a larger adverse effect than predicted by additive action. In this study only the mixtures of p-nitrobenzoic acid and $\mathrm{Zn}$ (at the concentration of $0.2 \mathrm{IC}_{50}$ and $0.5 \mathrm{IC}_{50}$ ) showed significantly synergistic interaction. The mechanism of synergism is presumably due to $p$-nitrobenzoic acid can provide an acid circumstance which can enhance the toxicity of $\mathrm{Zn}$. It is also found that the average $\mathrm{M}$ value of $-\mathrm{OH}$ substituted nitorbenzene (nitrophenols) and $\mathrm{Zn}$ is equal to 1.10, which is lower than the one (1.62) of $-\mathrm{NH}_{2}$ substituted nitrobenzene and $\mathrm{Zn}$. It demonstrates that the acidity will increase the joint toxicity. 


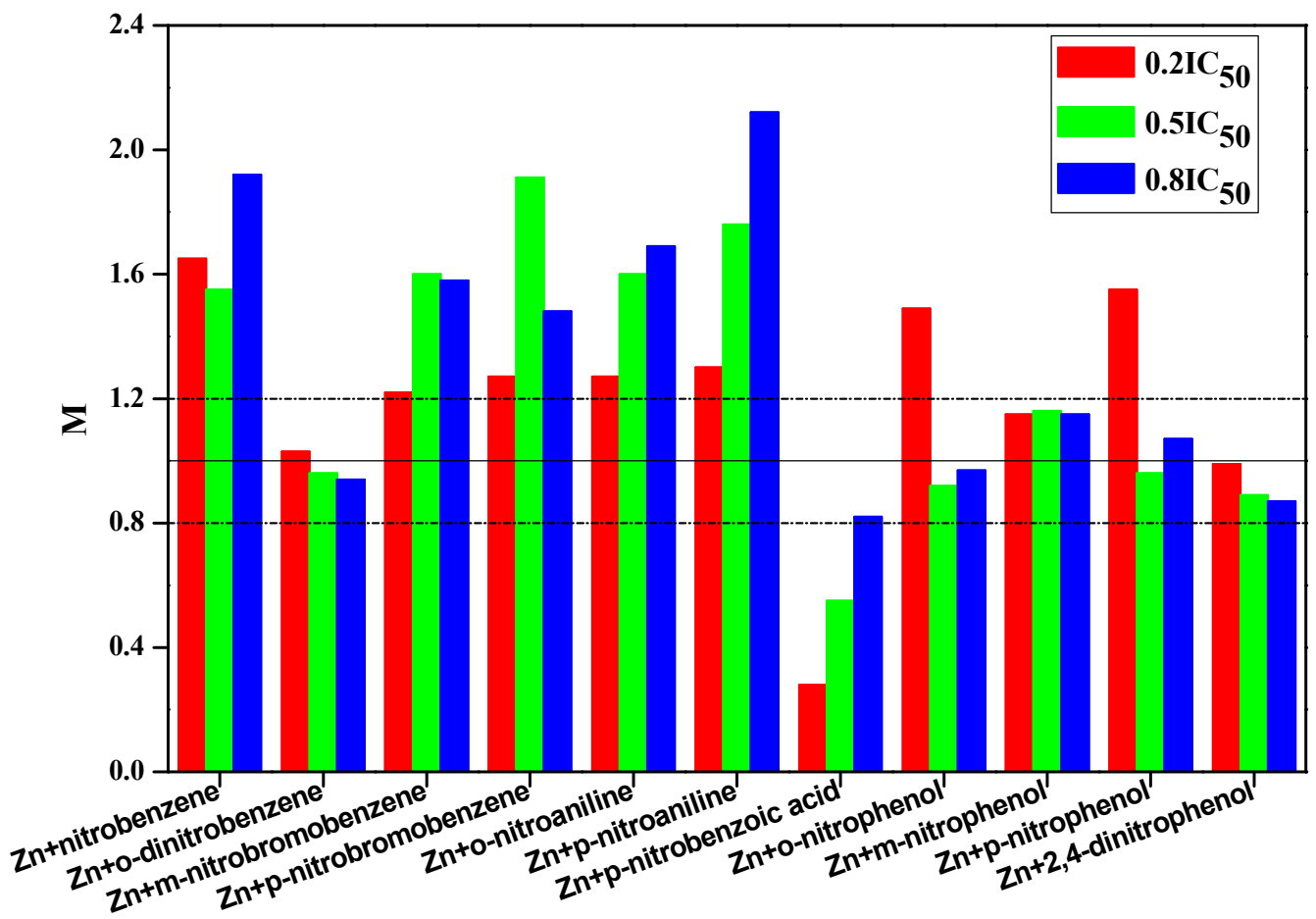

(a)

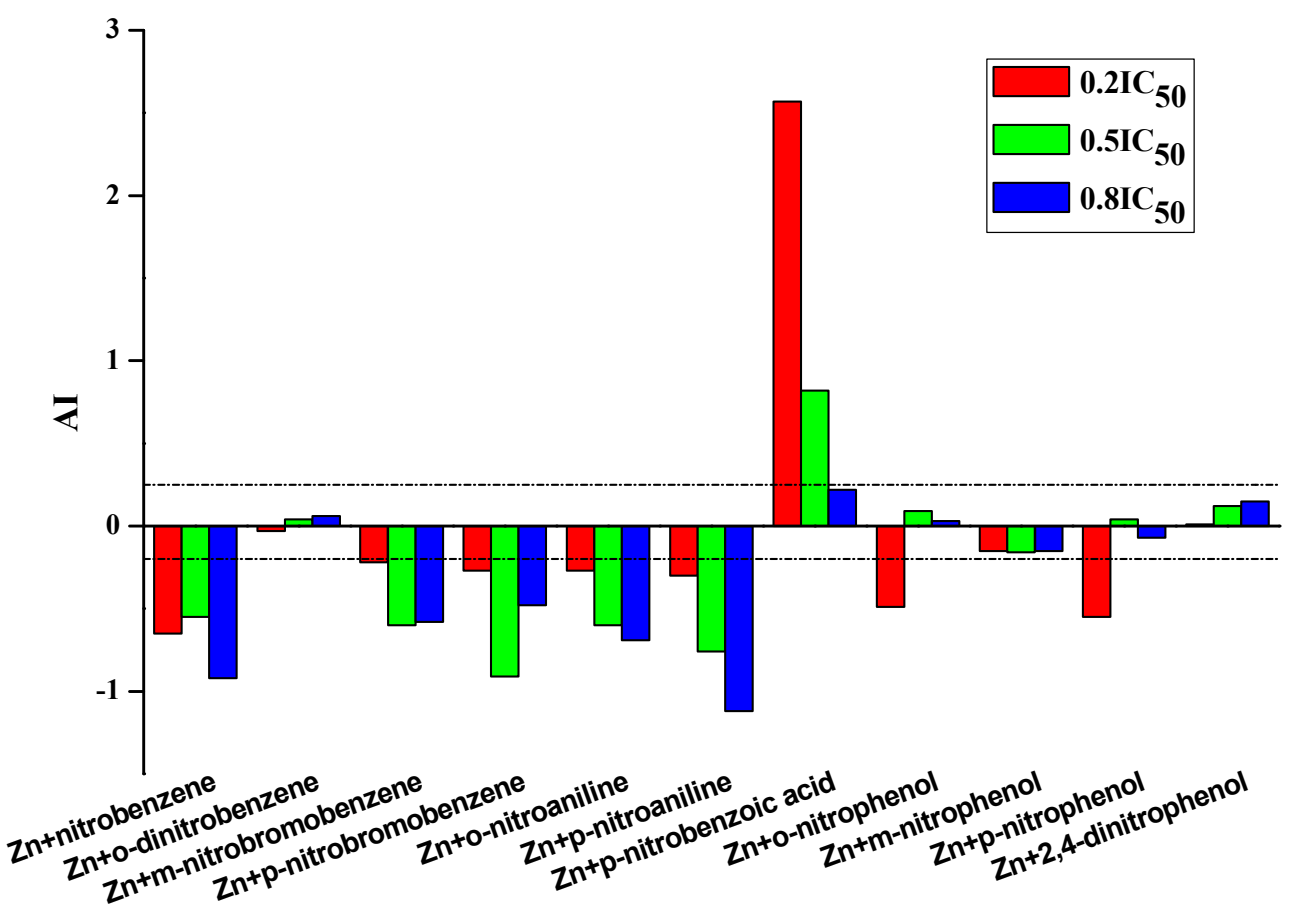

(b)

Figure 1. The evaluation results of joint toxicity of nitro-substituted benzenes and zinc bar by TU and AI methods ((a) values of $\mathrm{M}$; (b) values of $\mathrm{AI})$.

The result indicates that the joint toxicity is not only dependent on the Zn concentrations, but also on the functional groups substituted in the nitro-substituted benzenes. 


\subsection{QSAR Analysis of the Joint Toxicity of Nitro-Substituted Benzenes and Zn}

In order to identify and predict the toxicity at different combined ratios, the toxicology data of nitro-substituted benzenes combined with $\mathrm{Zn}$ at the concentrations of $0.2 \mathrm{IC}_{50} \mathrm{Zn}$, $0.5 \mathrm{IC}_{50} \mathrm{Zn}$, and $0.8 \mathrm{IC}_{50} \mathrm{Zn}$ were analyzed with Dragon descriptors of nitro-substituted benzenes using the stepwise linear regression method in the statistic package SPSS19.0, respectively. The different linear structure-toxicity models were obtained at different combined rations of $\mathrm{Zn}$ and nitro-substituted benzenes.

When $\mathrm{Zn}$ was set at the concentration of $0.2 \mathrm{IC}_{50}$, the QSAR equation built from the toxicology data of nitro-substituted benzenes in mixtures and descriptors was expressed as Equation (5)

$$
\begin{gathered}
\log 1 / \mathrm{IC}_{50}=20.540-53.948 \mathrm{VE} 2 \_\mathrm{B}(\mathrm{p})-0.033 \mathrm{TIC} 3 \\
n=11, \mathrm{R}^{2}=0.933, \mathrm{SE}=0.163, \mathrm{~F}=55.554, p<0.001
\end{gathered}
$$

Two descriptors (VE2_B(p) and TIC3) were introduced to the Equation (5). The first parameter entering the equations is average coefficient of the last eigenvector from Burden matrix weighted by polarizability $(\mathrm{VE} 2 \mathrm{~B}(\mathrm{p}))$ that is related to the polarizability of the molecule. It was found from Equation (4) that the toxicity of nitro-substituted benzenes in mixtures decreases with the increasing of VE2_B(p). The second is TIC3 that is total information content index (neighborhood symmetry of 3-order) which included in indices of neighborhood symmetry sub-block.

When $\mathrm{Zn}$ was set at the concentration of $0.5 \mathrm{IC}_{50}$, the QSAR equation built from the toxicology data of nitro-substituted benzenes in mixtures and descriptors was expressed as Equation (6):

$$
\begin{gathered}
\log 1 / \mathrm{IC}_{50}=3.760+1.100 \mathrm{Eig} 06 \_\mathrm{AEA}(\mathrm{dm}) \\
n=11, \mathrm{R}^{2}=0.856, \mathrm{SE}=0.232, \mathrm{~F}=53.318, p<0.001
\end{gathered}
$$

Eig06_AEA $(\mathrm{dm})$ standing for eigenvalue $\mathrm{n} .6$ from augmented edge adjacency matrices weighted by dipole moment is the only parameter in Equation (6). It belongs to the edge adjacency indices. Eig06_AEA $(\mathrm{dm})$ is positively correlated to the joint toxicity of nitro-substituted benzenes in mixtures when $\mathrm{Zn}$ was set at the medium concentration.

When $\mathrm{Zn}$ was set at the concentration of $0.8 \mathrm{IC}_{50}$, the QSAR equation built from the toxicology data of nitro-substituted benzenes in mixtures and descriptors was expressed as Equation (7):

$$
\begin{gathered}
\log 1 / \mathrm{IC}_{50}=3.908+1.511 \operatorname{Eig} 06 \_\mathrm{AEA}(\mathrm{dm}) \\
n=11, \mathrm{R}^{2}=0.937, \mathrm{SE}=0.201, \mathrm{~F}=133.351, p<0.001
\end{gathered}
$$

The joint toxicity of nitro-substituted benzenes is positively related to the parameter Eig06_AEA(dm) when those organic chemicals combined with $\mathrm{Zn}$ at high $\mathrm{Zn}$ concentration. Interestingly, the result showed that the same descriptor (Eig06_AEA(dm)) was chosen when nitro-substituted benzenes and $\mathrm{Zn}$ were combined at medium and high ratios. It implies that the toxicity of nitro-substituted benzenes correlates well with edge adjacency indices when they are combined with $\mathrm{Zn}$ at medium and high concentration in the present study. Whereas, it is found that other descriptors (VE2_B(p) and TIC3) are related to the toxicity of nitro-substituted benzenes in the mixture at the low concentration of $\mathrm{Zn}$. It is found from Equations (5)-(7) that combined ratio is a factor which will influence the joint toxicity and should be pay more attention. The result of joint action of nitro-substituted benzenes and $\mathrm{Zn}$ influenced by combined ratios is in line with literature research $[6,44]$. Therefore, it is necessary to establish different QSAR models to predict the joint toxicity at different combined ratios. It should be noted that it is improbable to find zinc pollution exactly at $0.2,0.5$ or 0.8 times $\mathrm{IC}_{50}$ in real environment. The combined ratios calculated by TUs in the present study represents 3 cases theoretically, namely, nitro-substituted benzenes $>\mathrm{Zn}$, nitro-substituted benzenes $\approx \mathrm{Zn}$ and nitro-substituted benzenes $<\mathrm{Zn}$. If nitro-substituted benzenes are more than $\mathrm{Zn}$ evaluated by their TUs in the real environment, descriptors of VE2_B(p) and TIC3 are more suitable 
to predict the toxicity; whereas, if $\mathrm{Zn}$ is dominant or approximately the same with nitro-substituted benzenes, descriptor Eig06_AEA(dm) is more suitable for prediction.

Satisfactory models were obtained at different combined ratios of nitro-substituted benzenes and Zn with $\mathrm{R}^{2}$ equal to $0.933,0.856$, and 0.937 , respectively. Table 4 lists the descriptors of nitro-substituted benzenes and the relative errors $[28,29]$ from Equations (5)-(7). As is shown in Table 4, only the relative error value of $p$-nitrophenol predicted by Equation (6) is over than $10 \%$ (relative error values $=10.2 \%$ ). The plot of the predicted values from Equations (5)-(7) versus the experimental values is shown in Figure 2.

Table 4. Descriptors of nitro-substituted benzenes and the relative errors from QSAR models.

\begin{tabular}{|c|c|c|c|c|c|c|}
\hline \multirow{2}{*}{ Compounds } & \multirow{2}{*}{ VE2_B(p) } & \multirow{2}{*}{ TIC3 } & \multirow{2}{*}{ Eig06_AEA(dm) } & \multicolumn{3}{|c|}{ Relative Error Values } \\
\hline & & & & Er.(1) ${ }^{a}$ & Er.(2) ${ }^{a}$ & Er.(3) ${ }^{a}$ \\
\hline 2,4-dinitrophenol & 0.265 & 61.487 & 1.000 & -0.024 & 0.050 & 0.007 \\
\hline$p$-nitrobenzoic acid & 0.249 & 59.487 & 1.000 & 0.048 & -0.054 & -0.029 \\
\hline$o$-nitroaniline & 0.282 & 54.000 & 0.057 & -0.037 & 0.042 & 0.062 \\
\hline$o$-nitrophenol & 0.284 & 54.603 & 0.203 & 0.026 & 0.042 & 0.001 \\
\hline nitrobenzene & 0.295 & 40.548 & -0.479 & 0.081 & 0.017 & 0.011 \\
\hline$p$-nitroaniline & 0.278 & 48.000 & 0.058 & -0.003 & -0.022 & 0.027 \\
\hline p-nitrophenol & 0.280 & 48.603 & 0.214 & -0.038 & -0.102 & -0.096 \\
\hline$o$-dinitrobenzene & 0.272 & 44.000 & 1.000 & 0.001 & 0.041 & 0.048 \\
\hline m-nitrophenol & 0.281 & 56.603 & -0.057 & 0.049 & 0.053 & 0.008 \\
\hline m-nitrobromobenzene & 0.275 & 51.303 & 0.181 & -0.017 & -0.022 & -0.004 \\
\hline$p$ - nitrobromobenzene & 0.274 & 43.303 & 0.427 & -0.021 & -0.016 & -0.014 \\
\hline
\end{tabular}

${ }^{a}$ Er. (1), Er. (2), and Er. (3) are relative errors from Equations (5)-(7) which are calculated as following: $\mathrm{Er}=\left(\mathrm{V}_{\text {pred. }}-\mathrm{V}_{\text {exp. }}\right) / \mathrm{V}_{\text {exp. }}\left(\mathrm{V}_{\text {pred. }}\right.$ and $\mathrm{V}_{\text {exp. }}$ are the experimental and predicted values, respectively $)$.

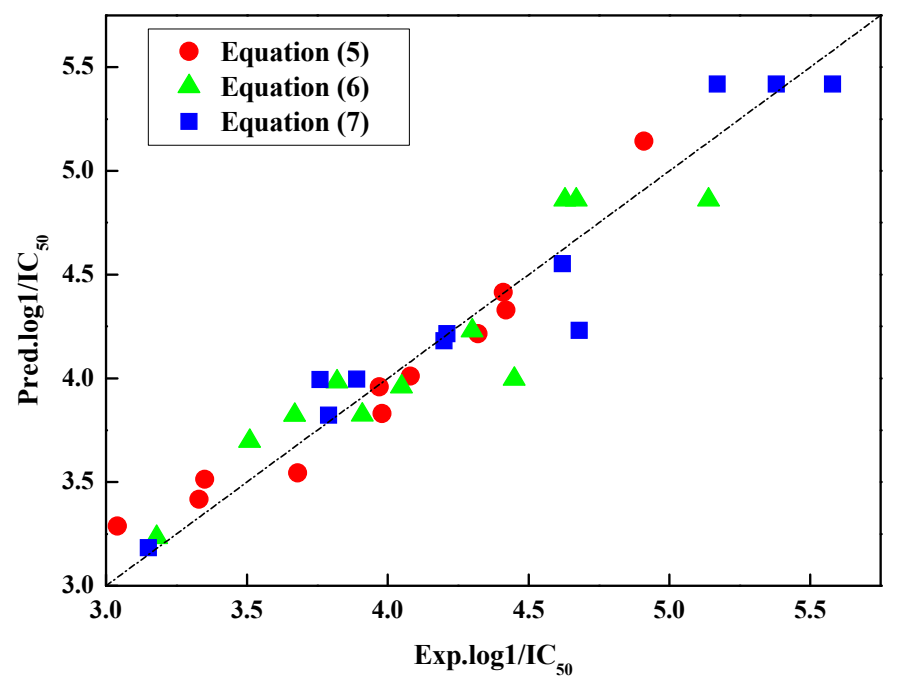

Figure 2. Plot of experimental and predicted values of nitro-substituted benzenes in mixtures from Equations (5)-(7).

Lower relative errors and good fit of predicted values and experimental values are found by Equations (5)-(7). It demonstrates that QSAR models developed in present paper are robust to predict the joint toxicity of nitro-substituted benzenes when combined with $\mathrm{Zn}$ at low, medium, and high concentrations.

\section{Conclusions}

The joint actions are mainly antagonism and simple addition when $\mathrm{Zn}$ combined with nitro-substituted benzenes. QSAR analysis shows that different descriptors could be chosen when nitro-substituted benzenes and $\mathrm{Zn}$ combined at low ratio. However, when nitro-substituted benzenes and $\mathrm{Zn}$ combined at medium and high ratios, the same descriptor was chosen in equations. At the 
$\mathrm{Zn}$ concentration of $0.2 \mathrm{IC}_{50}$, the binary joint effects of $\mathrm{Zn}$ and nitro-substituted aromatic compounds are mainly antagonism and the joint toxicity is negatively related to the descriptors called VE2_B(p) and TIC3. At the $\mathrm{Zn}$ concentration of $0.5 \mathrm{IC}_{50}$, the binary joint effects of $\mathrm{Zn}$ and nitro-substituted aromatic compounds are mainly antagonism and simple addition. At the $\mathrm{Zn}$ concentration of $0.8 \mathrm{IC}_{50}$, the binary joint effects are antagonism (45\%) and simple addition (55\%). At the $\mathrm{Zn}$ concentration of $0.5 \mathrm{IC}_{50}$ and $0.8 \mathrm{IC}_{50}$, the joint toxicity are both related to the descriptor Eig06_AEA(dm). It is found from Equations (5)-(7) that combined ratio is a factor which will influence the joint toxicity and should be pay more attention. The descriptors used are interpretable and contribute to express the joint interaction. QSAR models (Equations (5)-(7)) developed in present paper are simple, transparent and robust to predict the joint toxicity of nitro-substituted benzenes when combined with $\mathrm{Zn}$ at low, medium, and high concentrations.

Author Contributions: Data curation, S.Z. and C.L.; Investigation, S.Z., L.S., and Y.Z.; Methodology, D.Z. and X.L.; Visualization, X.Z. and W.Q.; Writing—original draft, S.Z.; Writing—review \& editing, L.S. and Y.Z.

Funding: This research is supported by the National Nature Science Foundation of China (21107012 and 21777022) and the Fundamental Research Funds for the Central Universities (2412018ZD014).

Conflicts of Interest: The authors declare no conflict of interest.

\section{References}

1. Krzykwa, J.C.; Saeid, A.; Jeffries, M.K.S. Identifying sublethal endpoints for evaluating neurotoxic compounds utilizing the fish embryo toxicity test. Ecotoxicol. Environ. Saf. 2019, 170, 521-529. [CrossRef]

2. Wang, S.; Yan, L.C.; Zheng, S.S.; Li, T.T.; Fan, L.Y.; Huang, T.; Li, C.; Zhao, Y.H. Toxicity of some prevalent organic chemicals to tadpoles and comparison with toxicity to fish based on mode of toxic action. Ecotoxicol. Environ. Saf. 2019, 167, 138-145. [CrossRef]

3. Wang, X.H.; Yu, Y.; Huang, T.; Qin, W.C.; Su, L.M.; Zhao, Y.H. Comparison of Toxicities to Vibrio fischeri and Fish Based on Discrimination of Excess Toxicity from Baseline Level. PLoS ONE 2016, 11, e0150028. [CrossRef] [PubMed]

4. Li, J.J.; Zhang, X.J.; Yang, Y.; Huang, T.; Li, C.; Su, L.M.; Zhao, Y.H.; Cronin, M.T.D. Development of thresholds of excess toxicity for environmental species and their application to identification of modes of acute toxic action. Sci. Total Environ. 2018, 616-617, 491-499. [CrossRef] [PubMed]

5. Souza, J.M.D.; Letícia, M.R.; Faria, D.B.G.D. The intake of water containing a mix of pollutants at environmentally relevant concentrations leads to defensive response deficit in male C57BL/6J mice. Sci. Total Environ. 2018, 628-629, 186-197. [CrossRef] [PubMed]

6. Li, X.F.; Zhou, Q.X.; Luo, Y.; Yang, G.; Zhou, T. Joint action and lethal levels of toluene, ethylbenzene, and xylene on midge (Chironomus plumosus) larvae. Environ. Sci. Pollut. Res. 2013, 20, 957-966. [CrossRef] [PubMed]

7. Altenburger, R.; Nendza, M.; Schüürmann, G. Mixture toxicity and its modeling by structure-activity relationships. Environ. Toxicol. Chem. 2003, 22, 1900-1915. [CrossRef]

8. He, H.; Chen, G.; Yu, J.; He, J.; Huang, X.; Li, S.; Guo, Q.; Yu, T.; Li, H. Individual and joint toxicity of three chloroacetanilide herbicides to freshwater Cladoceran Daphnia carinata. Bull. Environ. Contam. Toxicol. 2013, 90, 344-350. [CrossRef]

9. Küpper, H.; Andresen, E. Mechanisms of metal toxicity in plants. Metallomics 2016, 8, 269-285. [CrossRef]

10. Otitoloju, A.A. Relevance of joint action toxicity evaluations in setting realistic environmental safe limits of heavy metals. J. Environ. Manag. 2003, 67, 121-128. [CrossRef]

11. Shaw, J.R.; Dempsey, T.D.; Chen, C.Y.; Hamilton, J.W.; Folt, C.L. Comparative toxicity of cadmium, zinc, and mixtures of cadmium and zinc to daphnids. Environ. Toxicol. Chem. 2006, 25, 182-189. [CrossRef] [PubMed]

12. Cooper, N.L.; Bidwell, J.R.; Kumar, A. Toxicity of copper, lead, and zinc mixtures to Ceriodaphnia dubia and Daphnia carinata. Ecotoxicol. Environ. Saf. 2009, 72, 1523-1528. [CrossRef] [PubMed]

13. Qu, R.J.; Liu, J.Q.; Wang, L.S.; Wang, Z.Y. The toxic effect and bioaccumulation in aquatic oligochaete Limnodrilus hoffmeisteri after combined exposure to cadmium and perfluorooctane sulfonate at different $\mathrm{pH}$ values. Chemosphere 2016, 152, 496-502. [CrossRef] [PubMed] 
14. Kadoya, W.; Sierra-Alvarez, R.; Wong, S.; Abrell, L.; Mash, E.A.; Field, J.A. Evidence of anaerobic coupling reactions between reduced intermediates of 4-nitroanisole. Chemosphere 2018, 195, 372-380. [CrossRef] [PubMed]

15. D'Yachkov, P.N.; Kharchevnikova, N.V.; Zholdakova, Z.I. Quantum chemical metabolism-based simulation of carcinogenic potency of benzene derivatives. Int. J. Quantum. Chem. 2010, 110, 1402-1411. [CrossRef]

16. Jönsson, S.; Eriksson, L.A.; van Bavel, B. Multivariate characterisation and quantitative structure-property relationship modelling of nitro-substituted benzenes. Anal. Chim. Acta 2008, 621, 155-162.

17. Wu, X.; Cobbina, S.J.; Mao, G.; Xu, H.; Zhang, Z.; Yang, L. A review of toxicity and mechanisms of individual and mixtures of heavy metals in the environment. Environ. Sci. Pollut. Res. 2016, 23, 8244-8259. [CrossRef]

18. Meng, H.; Xia, Y.; Chen, H. Bioremediation of surface water co-contaminated with zinc (II) and linear alkylbenzene sulfonates by Spirulina platensis. Phys. Chem. Earth 2012, 47-48, 152-155. [CrossRef]

19. Piao, F.; Yokoyama, K.; Ma, N.; Yamauchi, T. Subacute toxic effects of zinc on various tissues and organs of rats. Toxicol. Lett. 2003, 145, 28-35. [CrossRef]

20. Crémazy, A.; Brix, K.V.; Wood, C.M. Chronic Toxicity of Binary Mixtures of Six Metals (Ag, Cd, Cu, Ni, Pb, and Zn) to the Great Pond Snail Lymnaea stagnalis. Environ. Sci. Technol. 2018, 52, 5979-5988. [CrossRef]

21. Obiakor, M.O.; Ezeonyejiaku, C.D. Copper-zinc coergisms and metal toxicity at predefined ratio concentrations: Predictions based on synergistic ratio model. Ecotoxicol. Environ. Saf. 2015, 117, 149-154. [CrossRef] [PubMed]

22. Fu, Z.; Wu, F.; Chen, L.; Xu, B.; Feng, C.; Bai, Y.; Liao, H.; Sun, S.; Giesy, J.P.; Guo, W. Copper and zinc, but not other priority toxic metals, pose risks to native aquatic species in a large urban lake in Eastern China. Environ. Pollut. 2016, 219, 1069-1076. [CrossRef]

23. Liu, J.; Qu, R.; Yan, L.; Wang, L.; Wang, Z. Evaluation of single and joint toxicity of perfluorooctane sulfonateand zinc to Limnodrilus hoffmeisteri: Acute toxicity, bioaccumulationand oxidative stress. J. Hazard Mater. 2016, 301, 342-349. [CrossRef] [PubMed]

24. Xu, Y.B.; Xu, J.X.; Chen, J.L.; Huang, L.; Zhou, S.Q.; Zhou, Y. Antioxidative responses of Pseudomonas fluorescens YZ2 to simultaneous exposure of Zn and Cefradine. Ecotoxicology 2015, 24, 1788-1797. [CrossRef] [PubMed]

25. Zhu, H.; Yan, B.; Zhang, F. Enrichment of heavy metals in fishes of Songhua River and its pollution assessment. J. Ecol. Rural Environ. 2010, 26, 492-496.

26. Li, X.R.; He, M.C.; Sun, Y.; Xia, X.H.; Yan, Y. Distribution of nitrobenzenes in the Yellow River from Xiaolangdi to Gaocun Research. Environ. Sci. 2006, 27, 513-518.

27. Gao, J.; Liu, L.; Liu, X.; Zhou, H.; Wang, Z.; Huang, S. Concentration level and geographical distribution of nitrobenzene in Chinese surface waters. J. Environ. Sci. 2008, 20, 803-805. [CrossRef]

28. Wang, D.L.; Gao, Y.; Lin, Z.F.; Yao, Z.F.; Zhang, W.X. The joint effects on Photobacterium phosphoreum of metal oxide nanoparticles and their most likely coexisting chemicals in the environment. Aquatic Toxicol. 2014, 154, $200-206$. [CrossRef] [PubMed]

29. Qu, R.J.; Wang, X.H.; Liu, Z.T.; Yan, Z.G.; Wang, Z.Y. Development of a model to predict the effect of water chemistry on the acute toxicity of cadmium to Photobacterium phosphoreum. J. Hazard Mater. 2013, 262, 288-296. [CrossRef]

30. Su, L.M.; Zhang, X.J.; Yuan, X.; Zhao, Y.H.; Zhang, D.M.; Qin, W.C. Evaluation of joint toxicity of nitroaromatic compounds and copper to Photobacterium phosphoreum and QSAR analysis. J. Hazard Mater. 2012, 241-242, 450-455. [CrossRef]

31. Su, L.M.; Zhao, Y.H.; Yuan, X.; Mu, C.F.; Wang, N.; Yan, J.C. Evaluation of combined toxicity of phenols and lead to Photobacterium phosphoreum and quantitative structure-activity relationships. Bull. Environ. Contam. Toxicol. 2010, 84, 311-314. [CrossRef] [PubMed]

32. Yuan, X.; Lu, G.H.; Su, L.M. Correlation study of toxicity of substituted phenols to river bacteria and their biodegradability in river water. Biomed. Environ. Sci. 2005, 18, 281-285. [PubMed]

33. Jin, H.; Wang, C.; Shi, J.Q.; Chen, L. Evaluation on joint toxicity of chlorinated anilines and cadmium to Photobacterium phosphoreum and QSAR analysis. J. Hazard Mater. 2014, 279, 156-162. [CrossRef]

34. Thomulka, K.W.; Abbas, C.G.; Young, D.A.; Lange, J.H. Evaluating median effective concentrations of chemicals with bioluminescent bacteria. Bull. Environ. Contam. Toxicol. 1996, 56, 446-452. [CrossRef]

35. Li, C.; Zheng, S.S.; Li, T.T.; Chen, J.W.; Zhou, J.H.; Su, L.M.; Zhang, Y.N.; Crittenden, J.C.; Zhu, S.Y.; Zhao, Y.H. Quantitative structure-activity relationship models for predicting reaction rate constants of 
organic contaminants with hydrated electrons and their mechanistic pathways. Water Res. 2019, 151, 468-477. [CrossRef] [PubMed]

36. Li, C.; Wei, G.L.; Chen, J.W.; Zhao, Y.H.; Zhang, Y.N.; Su, L.M.; Qin, W.C. Aqueous OH radical reaction rate constants for organophosphorus flame retardants and plasticizers: Experimental and modeling studies. Environ. Sci. Technol. 2018, 52, 2790-2799. [CrossRef]

37. Xu, S.; Nirmalakhandan, N. Use of QSAR models in predicting joint effects in multi-component mixtures of organic chemicals. Water Res. 1998, 32, 2391-2399. [CrossRef]

38. Marking, L.L.; Dawson, V.K. Method of assessment of toxicity or efficacy of mixtures of chemicals. US Fish Wildl. Serv. Invest. Fish Control 1975, 67, 8.

39. Nirmalakhandan, N.; Xu, S.; Trevizo, C. Additivity in microbial toxicity of nonuniform mixtures of organic chemicals. Ecotoxicol. Environ. Saf. 1997, 37, 97-102. [CrossRef] [PubMed]

40. Wang, D.; Shi, J.; Xiong, Y.; Hu, J.; Lin, Z.; Qiu, Y.; Cheng, J. A QSAR-based mechanistic study on the combined toxicity of antibiotics and quorum sensing inhibitors against Escherichia coli. J. Hazard Mater. 2018, 341, 438-447. [CrossRef]

41. Broderius, S.J.; Kahl, M.D.; Hoglund, M.D. Use of joint response to define the primary mode of toxic action for diverse industrial organic chemicals. Environ. Toxicol. Chem. 1995, 14, 1591-1605. [CrossRef]

42. Cedergreen, N. Quantifying synergy: A systematic review of mixture toxicity studies within environmental toxicology. PLoS ONE 2014, 9, e96580. [CrossRef] [PubMed]

43. Kepner, J. Synergy: The big unknowns of pesticide exposure. Pestic. You 2004, 23, 17-20.

44. Otitoloju, A.A. Evaluation of the joint-action toxicity of binary mixtures of heavy metals against the mangrove periwinkle Tympanotonus fuscatus var radula (L.). Ecotoxicol. Environ. Saf. 2002, 53, 404-415. [CrossRef]

(C) 2019 by the authors. Licensee MDPI, Basel, Switzerland. This article is an open access article distributed under the terms and conditions of the Creative Commons Attribution (CC BY) license (http:/ / creativecommons.org/licenses/by/4.0/). 